\title{
BMJ Global Health The need to reshape global food processing: a call to the United Nations Food Systems Summit
}

\author{
Carlos Augusto Monteiro, ${ }^{1}$ Mark Lawrence, ${ }^{2}$ Christopher Millett, ${ }^{3}$ Marion Nestle, ${ }^{4}$ \\ Barry M Popkin, ${ }^{5}$ Gyorgy Scrinis, ${ }^{6}$ Boyd Swinburn ${ }^{7}$
}

\begin{abstract}
To cite: Monteiro CA, Lawrence M, Millett C, et al. The need to reshape global food processing: a call to the United Nations Food Systems Summit. BMJ Global Health 2021;6:e006885. doi:10.1136/ bmjgh-2021-006885
\end{abstract}

Received 13 July 2021 Accepted 14 July 2021

Check for updates

(c) Author(s) (or their employer(s)) 2021. Re-use permitted under CC BY-NC. No commercial re-use. See rights and permissions. Published by BMJ.

${ }^{1}$ Department of Nutrition, School of Public Health, University of Sao Paulo, Sao Paulo, Brazil ${ }^{2}$ Institute for Physical Activity and Nutrition, School of Exercise and Nutrition Science, Deakin University, Geelong, Victoria, Australia

${ }^{3}$ Public Health Policy Evaluation Unit, School of Public Health, Imperial College London, London, UK

${ }^{4}$ Department of Nutrition and Food Studies, New York University, New York, New York, USA

${ }^{5}$ Carolina Population Center, University of North Carolina, Chapel Hill, North Carolina, USA ${ }^{6}$ School of Agriculture and Food, University of Melbourne, Melbourne, Victoria, Australia ${ }^{7}$ School of Population Health, University of Auckland, Auckland, New Zealand

Correspondence to Professor Carlos Augusto Monteiro; carlosam@usp.br

\section{INTRODUCTION}

The UN Food Systems Summit is taking place later this year at a crucial time. Food systems are manifestly failing to enhance human health, social equity or environmental protection. One symptom is the pandemic of obesity and related non-communicable diseases with their vast consequences. As we show here, one of the main drivers of this pandemic is the transformation in food processing. In the modern, globalised food system, useful types of food processing that preserve foods, enhance their sensory properties and make their culinary preparation easier and more diverse, have been and are being replaced by deleterious types of processing whose main purpose is to increase profits by creating hyperpalatable and convenient products that are grossly inferior imitations of minimally processed foods and freshly prepared dishes and meals. The Summit has a unique opportunity to confront this calamitous change, and to recommend effective policies and actions to UN agencies and member states.

\section{PROCESSING AND INDUSTRY}

The key issue here is the nature, purpose and extent of food processing. It is not processing as such. General criticism of food processing is too unspecific to be helpful. Most foods are processed in some way, and culinary preparations of fresh foods are usually made using processed ingredients. Some types of food processing contribute to healthful diets, but others do the opposite. ${ }^{1}$

At one extreme are minimal processes which mostly preserve or enhance whole foods, such as drying grains, pulses and nuts, grinding grains into flour and pasta, chilling or freezing fruits and vegetables, pasteurising milk and fermenting milk into yoghurt.

At the other extreme are industrial processes that convert food commodities such as wheat,
Summary box

In the modern, globalised food system, useful types of industrial food processing that preserve foods, enhance their sensory properties and make their culinary preparation easier and more diverse, have been and are being replaced by food ultra-processing.

- The main purpose of food ultra-processing is to increase profits by creating hyperpalatable and convenient food products that are grossly inferior imitations of minimally processed foods and freshly prepared dishes and meals.

- In the last decades, obesity, type 2 diabetes and related diseases have become global epidemics, leading the health systems of many countries to or beyond breaking point.

- Taken together, the totality of evidence summarised here shows beyond reasonable doubt that increased consumption of ultra-processed foods is a major contributor to the pandemic of obesity, type 2 diabetes and related diseases.

- The 2021 UN Food System has a unique opportunity to urge countries to implement policy interventions required to reduce ultra-processed food production, distribution and consumption, while simultaneously making fresh or minimally processed foods more available, accessible and affordable.

soy, corn, oils and sugar, into chemically or physically transformed food substances, formulated with various classes of additives into generally cheap to make, long duration substitutes to minimally processed foods and freshly prepared dishes and meals. The result is brand-named sugary, fatty and/or salty food and drink products which typically contain little or no whole food, are designed to be ready-to-consume anytime, anywhere and are highly attractive to the senses or even quasiaddictive. These products, including sweet and flavoured drinks, sweet or savoury snacks, reconstituted meat products and shelf-stable or frozen ready meals and desserts, are identified as ultra-processed foods. ${ }^{2}$ 
Criticisms of the food industry as a whole are also a mistake. Most of the very many millions of food farming, growing, rearing, making, distributing, selling and catering businesses throughout the world, notably in Asia, Africa and Latin America, deal solely or largely in fresh and minimally processed foods. These businesses and the foods they produce need to be encouraged, defended and supported.

By contrast, ultra-processed foods are mostly enabled, produced and sold by a small number of transnational corporations, some of whose turnovers exceed the revenues of many countries and make annual profits of US\$ billions. ${ }^{3}$ These corporations use their power to formulate, mass manufacture, distribute and aggressively market their products worldwide. ${ }^{4}$

These corporations shape scientific findings by funding in-house and university-based research, so as to defend and promote ultra-processed foods. ${ }^{5}$ They also exercise political power by intensive lobbying, donations and sponsorships, and until now have dissuaded most governments from adequately regulating their products and practices. ${ }^{6}$

Time-series food sales data indicate the explosive growth in manufacturing and consumption of ultra-processed foods worldwide. ${ }^{7}$ National dietary surveys show that ultraprocessed foods already make up 50\% or more of total dietary energy intake ${ }^{8}$ in high-income countries, with even higher consumption among children and adolescents. ${ }^{9}$ In middle-income countries, they now represent between 15\% and $30 \%$ of total energy intake ${ }^{8}$ but sales of ultra-processed foods are increasing fastest in these countries. ${ }^{10}$

\section{THE PANDEMIC OF OBESITY AND RELATED DISEASES AND ITS LINK WITH ULTRA-PROCESSING}

According to $\mathrm{WHO}$, worldwide prevalence of obesity has nearly tripled since the mid-1970s, and now over 650 million adults are obese, and 1.9 billion adults and over 370 million children and adolescents are overweight or obese (https://www.who.int/news-room/fact-sheets/ detail/obesity-and-overweight). No country has yet reversed these increases. Closely driven by the increase in obesity is a doubling of worldwide type 2 diabetes prevalence since 1980 , now affecting about 420 million people (https://www.who.int/news-room/fact-sheets/ detail/diabetes). Obesity, type 2 diabetes and related non-communicable diseases, including cardiovascular diseases and some common cancers, have become pandemics. Pre-COVID-19, health systems in most countries did not have the capacity to effectively treat dietinfluenced diseases. Now, many health systems are at or beyond breaking point struggling with COVID-19, the severity of which is significantly higher in people with obesity and related diseases.

Evidence of the general healthfulness of dietary patterns based on fresh and minimally processed foods and culinary preparations, and their protection against all forms of malnutrition, 'is noteworthy for its breadth, depth, diversity of methods, and consistency of findings'. ${ }^{11}$
But only in the last decade, with the advent of the NOVA food classification system that distinguishes ultraprocessed foods from minimally processed or processed foods, ${ }^{1}$ has the link between changes in types of food processing and the pandemic of obesity and related diseases been revealed. Evidence here includes:

- Three meta-analyses of findings from epidemiological studies, including large, long-duration, carefully conducted cohort studies, show dose-response associations between consumption of ultra-processed foods and obesity, abdominal obesity, type 2 diabetes, dyslipidaemias, metabolic syndrome, depression, cardio and cerebrovascular diseases and all-cause mortality. ${ }^{12-14}$

- Analysis of national dietary or food purchase surveys in middle-income or high-income countries shows that the higher the dietary share of ultra-processed foods, the higher the obesogenic dietary nutrient profiles. These are characterised by higher energy density, free sugars, unhealthy fats and sodium, and lower protein and dietary fibre. ${ }^{8}$

- Epidemiological and experimental studies indicate that ultra-processed foods may increase risks for obesity and related diseases in other ways beyond their nutritional composition. These include structural and physical properties that blunt satiety signalling, organoleptic characteristics associated with higher energy intake rate, neo-formed substances and migrated packaging materials that are endocrine disruptors, additives that promote pro-inflammatory microbiome, and reduced thermic effect that decreases total energy expenditures. ${ }^{12-14}$

- A randomised controlled cross-over trial shows that consuming a high ultra-processed diet causes a highly significant increase in ad libitum calorie intake and consequent weight gain. Over a 2-week period, 20 young adults following a diet with $83 \%$ of energy from ultra-processed foods consumed approximately 500 more kcal per day than when they followed a diet with no ultra-processed foods. Participants gained $0.9 \mathrm{~kg}$ at the end of the 2 weeks with the ultra-processed diet and lost $0.9 \mathrm{~kg}$ at the end of the non ultra-processed diet, mostly of body fat. ${ }^{15}$

- A longitudinal ecological study of 80 countries from 2002 to 2016 shows a direct association between changes in annual per capita volume sales of ultraprocessed foods and corresponding changes in population adult body mass index. ${ }^{16}$

Taken together, the totality of evidence summarised here shows beyond reasonable doubt that increased consumption of ultra-processed foods is a major contributor to the pandemic of obesity and related diseases. There is also mounting evidence of the harmful effects of the ultraprocessed food industry on the planet, through its global demand for cheap ingredients that destroy forests and savannah, its displacement of sustainable farming, and its resource-intensive manufacturing and packaging. ${ }^{.7}$ 


\section{POLICY RESPONSES}

To begin with, the UN Food Systems Summit should urge international and national health and food and nutrition authorities to review their dietary guidelines to emphasise preference for fresh or minimally processed foods and avoidance of ultra-processed foods, in line with guidelines developed, for example, by the WHO/Pan American Health Organization, ${ }^{18}$ and issued in several LatinoAmerican countries, and now also in France, Belgium, and Israel.

At the same time, national governments should be urged to use fiscal measures, marketing regulations, bold mandatory front-of-pack labelling schemes and food procurement policies, all designed to promote the production, accessibility and consumption of a rich variety of fresh or minimally processed foods, and to discourage the production, distribution and consumption of ultraprocessed foods, as now done in several countries. ${ }^{19}$

Current food and nutrition policies are mostly intended to encourage food manufacturers to reformulate their products by reducing the use of salt, sugar or unhealthy fats. There is a role for strong regulations that effectively limit the levels of these components, but reformulation alone will not turn ultra-processed products into healthy foods, ${ }^{20}$ as in effect recently acknowledged in one internal document from one leading ultra-processed food corporation - "some of our categories and products will never be 'healthy' no matter how much we renovate" (https://www.ft.com/ content/4c98d410-38b1-4be8-95b2-d029e054f492). Policies should instead stimulate the entire manufacturing industry to maintain, develop or improve processing methods that prolong the duration of whole foods, enhance their sensory properties and make their culinary preparation easier and more diverse. Ultra-processed foods should be replaced by processed foods with limited levels or absence of added salt, sugar or unhealthy fats or, preferably, by minimally processed foods. ${ }^{20}$

\section{CONCLUSIONS}

Food systems are failing. This is most clearly shown by what are now the pandemics of obesity and type 2 diabetes, of which ultra-processed food is a main contributor. The UN Food Systems Summit should urge member states to implement multiple policy interventions to reduce ultraprocessed food production, distribution and consumption, while simultaneously making fresh or minimally processed foods more available, accessible and affordable.

Twitter Carlos Augusto Monteiro @CMonteiro_USP

Acknowledgements This paper expands a one-page submission made by the authors to the UN Food Systems Summit within Solution Cluster 2.2.1 (food environment).

Contributors All authors contributed to the ideas presented in the manuscript. CAM wrote the manuscript. All authors contributed to redrafting and editing.

Funding The authors have not declared a specific grant for this research from any funding agency in the public, commercial or not-for-profit sectors.

Competing interests None declared.

Patient consent for publication Not required.
Provenance and peer review Not commissioned; internally peer reviewed.

Data availability statement All data relevant to the study are included in the article.

Open access This is an open access article distributed in accordance with the Creative Commons Attribution Non Commercial (CC BY-NC 4.0) license, which permits others to distribute, remix, adapt, build upon this work non-commercially, and license their derivative works on different terms, provided the original work is properly cited, appropriate credit is given, any changes made indicated, and the use is non-commercial. See: http://creativecommons.org/licenses/by-nc/4.0/.

\section{REFERENCES}

1 Monteiro CA, Cannon G, Moubarac J-C, et al. The UN decade of nutrition, the NOVA food classification and the trouble with ultraprocessing. Public Health Nutr 2018;21:5-17.

2 Monteiro CA, Cannon G, Levy RB, et al. Ultra-processed foods: what they are and how to identify them. Public Health Nutr 2019;22:936-41.

3 Monteiro CA, Cannon G. The Impact of Transnational "Big Food" Companies on the South: A View from Brazil. PLoS Med 2012;9:7.

4 Wood B, Williams O, Nagarajan V, et al. Market strategies used by processed food manufacturers to increase and consolidate their power: a systematic review and document analysis. Global Health 2021;17:1-23.

5 Nestle M. Unsavory truth: how food companies skew the science of what we eat. New York: Basic Books, 2018.

6 Mialon M, Gomes FdaS, da Silva Gomes F. Public health and the ultra-processed food and drink products industry: corporate political activity of major transnationals in Latin America and the Caribbean. Public Health Nutr 2019;22:1898-908.

7 Baker P, Machado P, Santos T, et al. Ultra-processed foods and the nutrition transition: global, regional and national trends, food systems transformations and political economy drivers. Obes Rev 2020;21:e13126.

8 Monteiro CA, Cannon G, Lawrence M. Ultra-processed foods, diet quality, and health using the NOVA classification system. Rome: FAO, 2019. http://www.fao.org/publications/card/en/c/CA5644EN/

9 Khandpur N, Neri DA, Monteiro C, et al. Ultra-processed food consumption among the paediatric population: an overview and call to action from the European childhood obesity group. Ann Nutr Metab 2020;76:109-13.

10 Moodie R, Bennett E, Kwong EJL, et al. Ultra-Processed Profits: The Political Economy of Countering the Global Spread of UltraProcessed Foods - A Synthesis Review on the Market and Political Practices of Transnational Food Corporations and Strategic Public Health Responses. Int J Health Policy Manag 2021. doi:10.34172/ ijhpm.2021.45. [Epub ahead of print: 24 May 2021].

11 Katz DL, Meller S. Can we say what diet is best for health? Annu Rev Public Health 2014;35:83-103.

12 Askari M, Heshmati J, Shahinfar H, et al. Ultra-processed food and the risk of overweight and obesity: a systematic review and metaanalysis of observational studies. Int J Obes 2020;44:2080-91.

13 Pagliai G, Dinu M, Madarena MP, et al. Consumption of ultraprocessed foods and health status: a systematic review and metaanalysis. Br J Nutr 2021; ;;125:308-18. 14.

14 Lane MM, Davis JA, Beattie S, et al. Ultraprocessed food and chronic noncommunicable diseases: a systematic review and metaanalysis of 43 observational studies.. Obes Rev 2021;22:e13146.

15 Hall KD, Ayuketah A, Brychta R, et al. Ultra-processed diets cause excess calorie intake and weight gain: an inpatient randomized controlled trial of AD libitum food intake. Cell Metab 2019;30:67-77.

16 Vandevijvere S, Jaacks LM, Monteiro CA, et al. Global trends in ultraprocessed food and drink product sales and their association with adult body mass index trajectories. Obes Rev 2019;20(Suppl 2):10-19.

17 Seferidi P, Scrinis G, Huybrechts I, et al. The neglected environmental impacts of ultra-processed foods. Lancet Planet Health 2020;4:e437-8.

18 Popkin BM, Barquera S, Corvalan C, et al. Towards unified and Impactful policies to reduce ultra-processed food consumption and promote healthier eating. Lancet Diabetes Endocrinol 2021;9:462-70.

19 Pan American Health Organization. Ultra-Processed food and drink products in Latin America: sales, sources, nutrient profiles, and policy implications. Washington, DC: PAHO, 2019. https://iris.paho. org/handle/10665.2/51094

20 Scrinis G, Monteiro CA. Ultra-processed foods and the limits of product reformulation. Public Health Nutr 2018;21:247-52. 